\title{
DEVELOPMENT OF DRYING SCHEDULES FOR RUBBER AND PINE TIMBER FOR THE DEHUMIDIFICATION KILN DRYING
}

\author{
R S Sujith Rathnayake and H S Amarasekera \\ University of Sri Jayewardenepura, \\ Nugegoda.
}

\begin{abstract}
Most of the timber in Sri Lanka is used in unseasoned state or seasoned using conventional kilns which use fuel wood boilers or open fires as a heating source. A study has been conducted to introduce dehumidification drying kiln, which is easy to fabricate and consumes less energy hence ideal for small scale timber industrics.
\end{abstract}

Experiments were conducted to investigate drying behaviour, 10 develop kiln schedules and 10 evaluate the developed kiln schedules for Pine (Pinus raribaea) and Rubber (He'ea brasiliensis) timber. The dehumidification kiln used in the present study is locally labricated and it has 25 cubic feet capacity. The temperature of the kiln can be increased $1050^{\prime \prime} \mathrm{C}$ and relative humidity can be reduced to $16 \%$.

Drying rate. percentage shrinkage and drying defects were observed for these two species by drying $215 \times 75 \times 300 \mathrm{~mm}$ stakes in temperature, humidity and air circulation controlled mini chamber. It was lound that Pimas caribaea was relatively fast drying timber compared with Hevea brasiliensis. However. H. brasiliensis showed higher percentage shrinkage and defects over $P$. carlogea during the early stages of drying. This indicates that /I. brasiliensis should be dried slowly at the initial stages of drying.

Three kiln schedules with slow. medium and fast drying rates were developed for seasoning $25 \mathrm{~mm}$ planks based on the results of drying behaviour. Drying rate, drying efliciency, drying delects, drying cost and thermal efliciency of these kiln schedules were evaluated by drying $25 \times 150 \times 1000 \mathrm{~mm}$ sample boards in the dehumidification kiln. Compared with conventional kiln scasoning, dehumidification kiln seasoning gave higher quality dried timber with more than $90 \%$ drying efficiency and faster drying rate, while maintaining higher thermal and economical efficiency.

It is concluded that higher quality $H$. brasiliensis and $P$. caribata dried timber can be obtained at a faster rate by drying them using these scinedules in the dehumidification drying kiln compared with conventional drying.

Proceedings of the Fourth Annual Forestry and Enviromment Sympesium 1998 of the Depestment of Forestry and Enviremmental Science, University of Sri Jayewardenepura, Sri Lanka 